\title{
COMPARATIVE ANALYSIS OF MACHINABILITY OF NITINOL ALLOY USING WEIGHTED RADAR DIAGRAM
}

\author{
Małgorzata Kowalczyk, Czesław Niżankowski \\ Cracow University of Technology, Production Engineering Institute, Poland \\ Corresponding author: \\ Matgorzata Kowalczyk \\ Cracow University of Technology \\ Production Engineering Institute \\ Al. Jana Pawta II 37, 31-864 Cracow, Poland \\ phone: (+48) 12 374-32-50 \\ e-mail: kowalczyk@mech.pk.edu.pl
}

Received: 24 May 2016

Accepted: 7 November 2017

\begin{abstract}
The paper presents an attempt to analyze comparative machinability of two different varieties of nitinol alloy type, or compare the susceptibility of these materials to change the volume, shape and dimension of adopted machining conditions. The machinability of the material can not be fully determined numerically by only one independent factor. Therefore multivariate analysis technique of weighted diagram radar was developed by authors. This technique allowed for the comprehensive identification machinability analyzed varieties of nitinol alloy exclusively on the basis of the specified in literature directional material properties and general recommendations tool manufacturers on the cutting conditions. In the paper the full usefulness of this technique to demonstrate the differences in machinability of different varieties of the same species alloy, without the need for lengthy and cost-intensive experimental trials was presented.
\end{abstract}

KEYWORDS

machinability, nitinol (TiNi), weighted radar diagram.

\section{Introduction}

Nitinol is a trade name of a non-ferrous alloys with shape memory in which the dominant components are nickel and titanium. TiNi alloys are an important class of shape memory alloys. In 1938 Greninger and Mooradian1 first observed the shape memory effect for copper-zinc alloys $(\mathrm{Cu}-\mathrm{Zn})$ and copper-tin alloys (Cu-Sn). Yet nearly 30 years elapsed until Buehler and his colleagues applied in 1965 for the first patent for a nickel-titanium alloy, called Nitinol, from the Naval Ordnance Laboratory. They exhibit not only shape memory effect SME, but also unusual pseudoelasticity and high damping capacities. These properties along with their superior ductility, fatigue strength, and corrosion resistance, have resulted in many applications. The basic characteristics of TiNi (shape memory effect), involving transformational crystallography, shape memory phenomena, and the effects of thermo-mechanical treatments, have been intensively investigated
The microstructure characteristic of Nitinol is that it is in a martensitic phase at lower temperatures, but in an austenitic phase at elevated temperatures. Nitinol exhibits two unique mechanical behaviors: thermal shape memory and superelasticity, which are illustrated in the stress-straintemperature diagram in Fig. 1. The phase transformation that occurs in Nitinol is dependent on the start and final thermal transitions of the austenite and martensite crystalline phases. It is important to understand the diffusionless transformation to predict the mechanical behavior.

Figure 1 shows the path that thermal shape memory takes place. Assuming Nitinol initially is in an austenitic state at the origin point $\mathrm{O}$. With no applied stress as Nitinol is cooled along path $\mathrm{O} \rightarrow \mathrm{A}$ below martensite finish temperature (Mf), complete transformation from austenite to martensite (twinned) will occur. The material is deformed through reorientation and detwinning of martensite along path $\mathrm{A} \rightarrow \mathrm{B}$. Then, load releasing on path $\mathrm{B} \rightarrow \mathrm{C}$ 
will cause elastic unloading of the reoriented detwinned martensite and the material stays deformed. On heating above the austenite finish temperature (Af), the material transforms from martensite to austenite and recovers the pseudoplastic deformation "remembering" its former shape. The austenitic Nitinol can be loaded along the path $\mathrm{O} \rightarrow \mathrm{E}$ (Fig. 1) above the austenite finish temperature (Af) through a stress-induced transformation to martensitic state. A large elastic strain up to $11 \%$ can be achieved. Upon unloading along the path $\mathrm{E} \rightarrow \mathrm{O}$, the material will transform back to austenitic state and the superelastic deformation will be recovered, demonstrating a hysteresis loop in the stress-strain diagram $[1,2]$.

Nitinol, a nearly equiatomic nickel-titanium shape memory alloy, has wide applications in cardiovascular stents, microactuators, and high damping devices. Nitinol alloy is used both in the construction of parts of machines and equipment as well as in medicine. In the first case usually are made portions of the temperature of safety valves, fire detectors, the regulatory systems in the radiators of regulating the flow of fuel and air in carburetors, automatic systems, opening windows in greenhouses, etc.

And in the second case of nitinol are made specialized implants for surgery, orthopedics and ortho- dontics for the treatment of spinal diseases, osteoporosis, fractures rib, malocclusion. Another sphere of application is the arms industry, military and aerospace industry, and industrial robots [1].

The concept of machinability often referred to is synonymous with the workability of materials machining. Machinability is the ability of a material to change shape, dimensions and physical (or sometime chemical) properties in a machining process. Machinability of each material is very important utilitarian because the better is the machinability it is more productive and less expensive production. Machinability determines also the quality of the maschined parts. In this aspect can be used as an criterion in machining process diagnostics [3].

Machinability cannot be completely determined with only one, qualitative indicator because many factors, such as chemical composition, structure, method, form and type of machining, type of the wedge profile and cutting properties of the wedge, cutting parameters, the machine tool and its characteristics, the method of attachment of the workpiece, type and method of cutting fluids application etc., influence the process. In industrial practice from all machinability indicators, wedge life, cutting forces, surface roughness, and type of chip or cutting temperature can be distinguished.

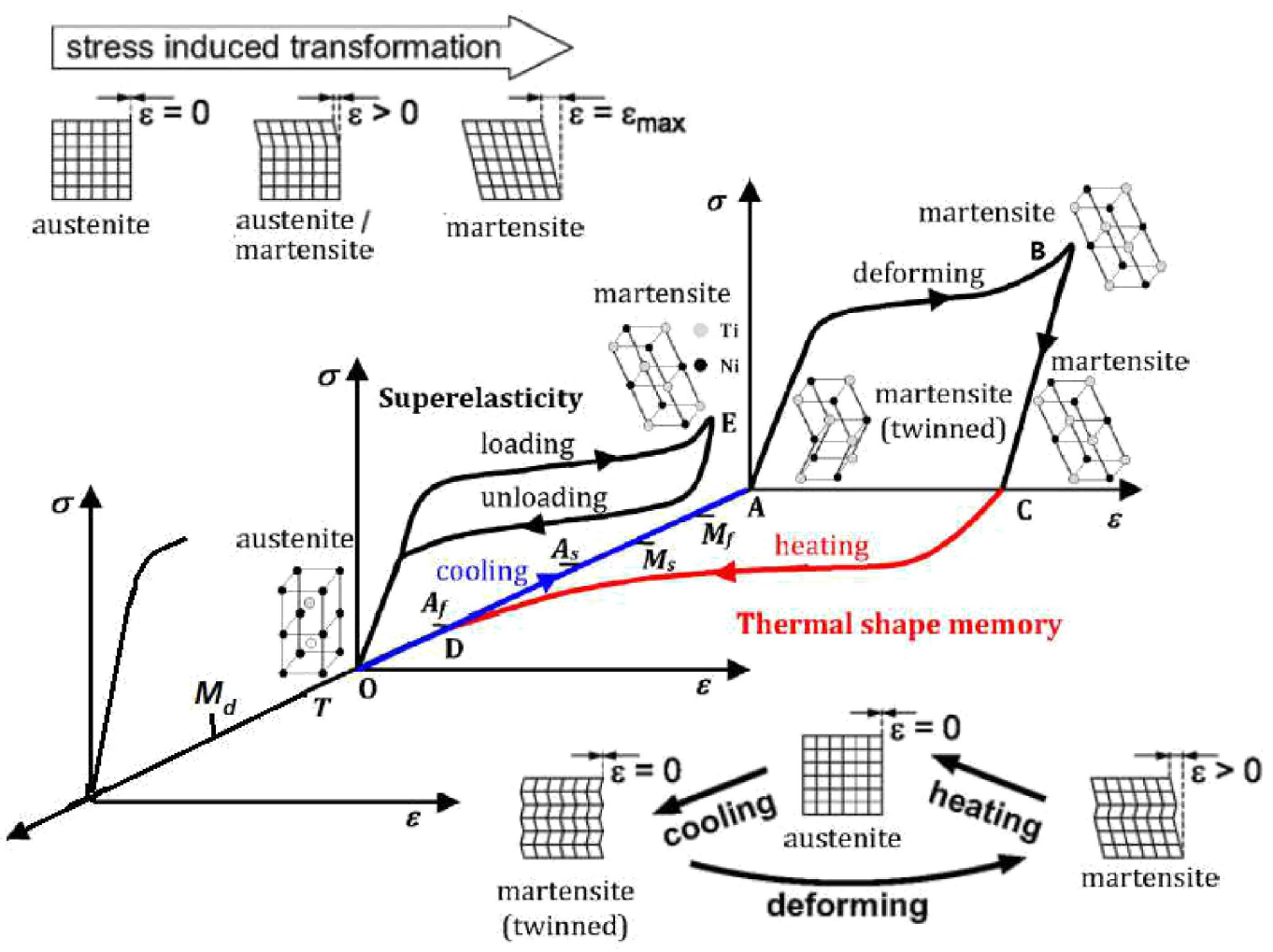

Fig. 1. Temperature dependent stress-strain behaviour of shape memory alloys $[1,2]$. 
Many experiments show the evidence that there is no univocal relation between various machinability indicators, and therefore on the basis of knowledge of one of these indicators have not always possible to enough judge values of the other indicators. In the machine technology often encounter situations in which the machinability of the material defined in one of the best indicators as the other turns out to be the worst. Hence, for adequate machinability estimation one should refer to the indicator, which was basic for the process definition. According to Polish technological standards absolute or relative indicators are used. Absolute machinability indicators are function of the examined factors and they have not only values but also dimensions. Relative machinability indicators are determined by providing comparison of the absolute indicators of the examined material to the absolute indicators of the model material. Relative indicators are absolute numbers and do not have dimension. According to Polish standards PNISO 3685 model materials for steel and cast iron are respectively hot-rolled steel 45 and pearlitic cast iron with flake graphite of a class 250-200 (220) HB.

Irrespective of these indicators used machinability always be aware of the interaction of the three areas that affect the process of constituting the machinability: the workpiece, machines and tools.

\section{Current state of knowledge of the machinability of NiTi alloy}

Shape memory alloys are metals, which exhibit two very unique properties, pseudoelasticity and the shape memory effect. The nickel-titanium (NiTi) alloys are one type of these materials; they present additional advantages such as biocompatibility, high ductility, and high strength to weight ratio, good fatigue and corrosion resistance, high damping capacities.

Due to their specific properties NiTi alloys are known to be difficult-to-machine materials particularly by using conventional techniques. Their high ductility, high degree of strain hardening, poor thermal conductivity, very low „effective” elastic modulus and unconventional stress-strain behavior are the main properties responsible for their poor machinability.

As shown in Fig. 2a, machining causes severe tool wear. The machinability of NiTi significantly depends on the cutting speed and feed rate, which should be chosen high enough. Poor chip breaking and the formation of burrs is another problem that can be attributed to the high ductility as well as unconventional stress-strain behavior
(Fig. 2b). Despite the optimization of machining parameters, tool wear still remains a problem in machining of these alloys $[1,4,5-12]$.

a)

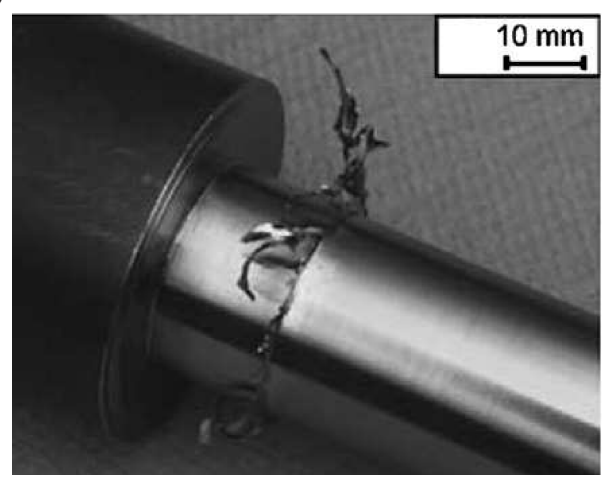

b)

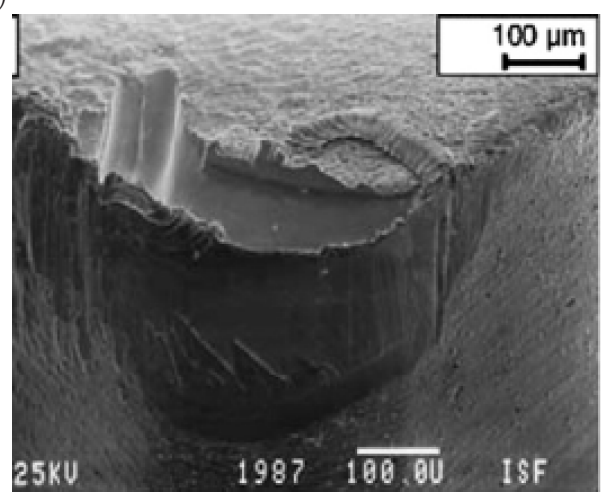

Fig. 2. Major drawbacks in machining NiTi shape memory alloys: a) formation of burrs after turning, b) tool wear $[9,13]$.

\section{Description of the weighted radar diagram technique}

The multicriterial analysis of a product (i.e. finished good, process or service) fitness based on the radar diagram has been commonly known and recognized technical-economic analysis technique for several ten years. It belongs to the group of quality tools and techniques [2]. This technique is also known as the spider web technique and features simple actions, clarity of visualizations and usually well describes the product in extent of considered criteria. It is often used to compare products of the same type (e.g. military aircrafts) based on the commonly recognized criterial parameters. The monotonic increase of such parameters indicates the higher product class (e.g. the speed of take-off climbing, operational ceiling and payload, etc.). Observing such prepared radar diagrams helps to compare individual features or properties for the products of similar type, as the values of considered features or properties are assessed with- 
out units of measure and indicated on evenly scaled axes originating from the center of the spider web. Low values are positioned close to the center of the spider web, while higher values are more distant. As separate points assigned to individual properties are linked, the polygonal inscribed in the original spider web is created [the white paper about productivity]. The area of such a polygonal and its position suggest the fitness level of analyzed product in the given application field or against the master product. That is why the engineers of internationally recognized tooling company SECO TOOLS have decided to use the radar diagram technique in order to analyze the machinability of various steel types, taking the structural steel 45 as a machinability master $[14,15]$.

For this reason, on five axes of the spider web they have prepared the evenly positioned, unitless ten-grade scales, for which the second stage was assigned each time to the master properties. Based on the general rule (higher values mean more points on the scale), they have predicted the machinability of analysed materials by assigning each axis to a separately taken material properties (cutting edge adhesion, material hardening during deformation, thermal conductivity, hardness and abrasibility), then they have linked points on the axes to create a pentagon. Example analysis results have been presented on Fig. 3 relative to the duplex corrosion resistant steel and CGI steel. Note that this technique disallows explicit indication of the material with best machinability, but suggest only some trends of process so- lutions while selecting the machining conditions of considered materials.

Considering this inconvenience, the white paper authors have decided to modify this technique by creating and further using weighted radar diagram. In such a modified technique, all radial axes originating in the spider web center have scale on both sides, whereas the right hand side of axis has the ten-point numerical scale, and the left hand side of axis is assigned to physical properties using numerical or descriptive values. Moreover, each axis on the weighted radar diagram ends with a circle, which is divided into two areas. The lower area contains the material property weigh, which is assigned by the authors based on the expert knowledge, whereas the upper area of the circle contains the point number achieved by the given material property (by multiplying point number corresponding to a material property value by a weight of this property) (Fig. 4). Once all the mentioned above actions for six axes of weighted radar diagram are done these axes are: hardness, thermal conductivity, abrasiveness (use $V B_{\max }$ to analyse), material structure, strain hardening factor (use $D n=$ yield strength/ultimate tensile strength to analyse) and specific cutting force $k c$, we can calculate the machinability for each analyzed material, by adding up number of points calculated for each of six material properties. The further step is to visualize achieved machinability values for materials being compared in form of histograms and spatial 3D radar diagrams [16].

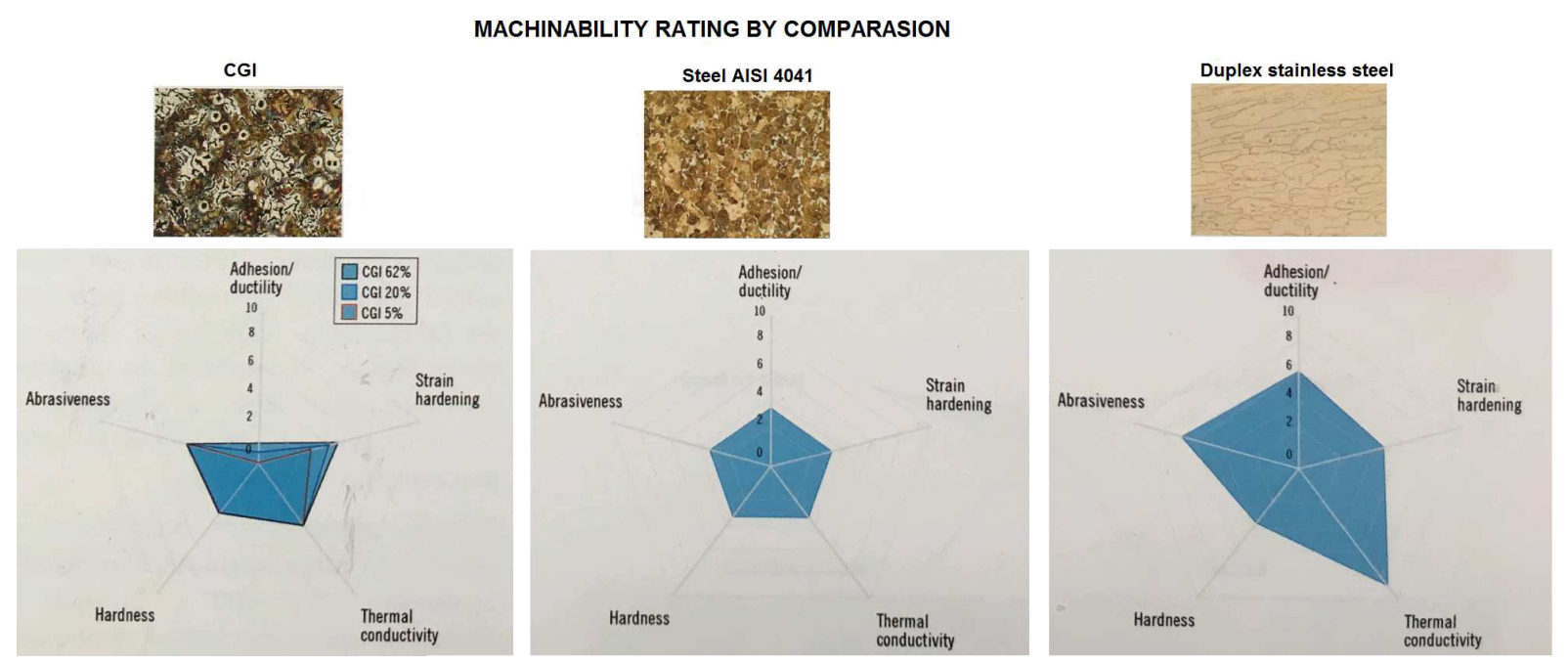

Fig. 3. Example comparison of machinability for various steel types using the radar diagram technique [15]. 


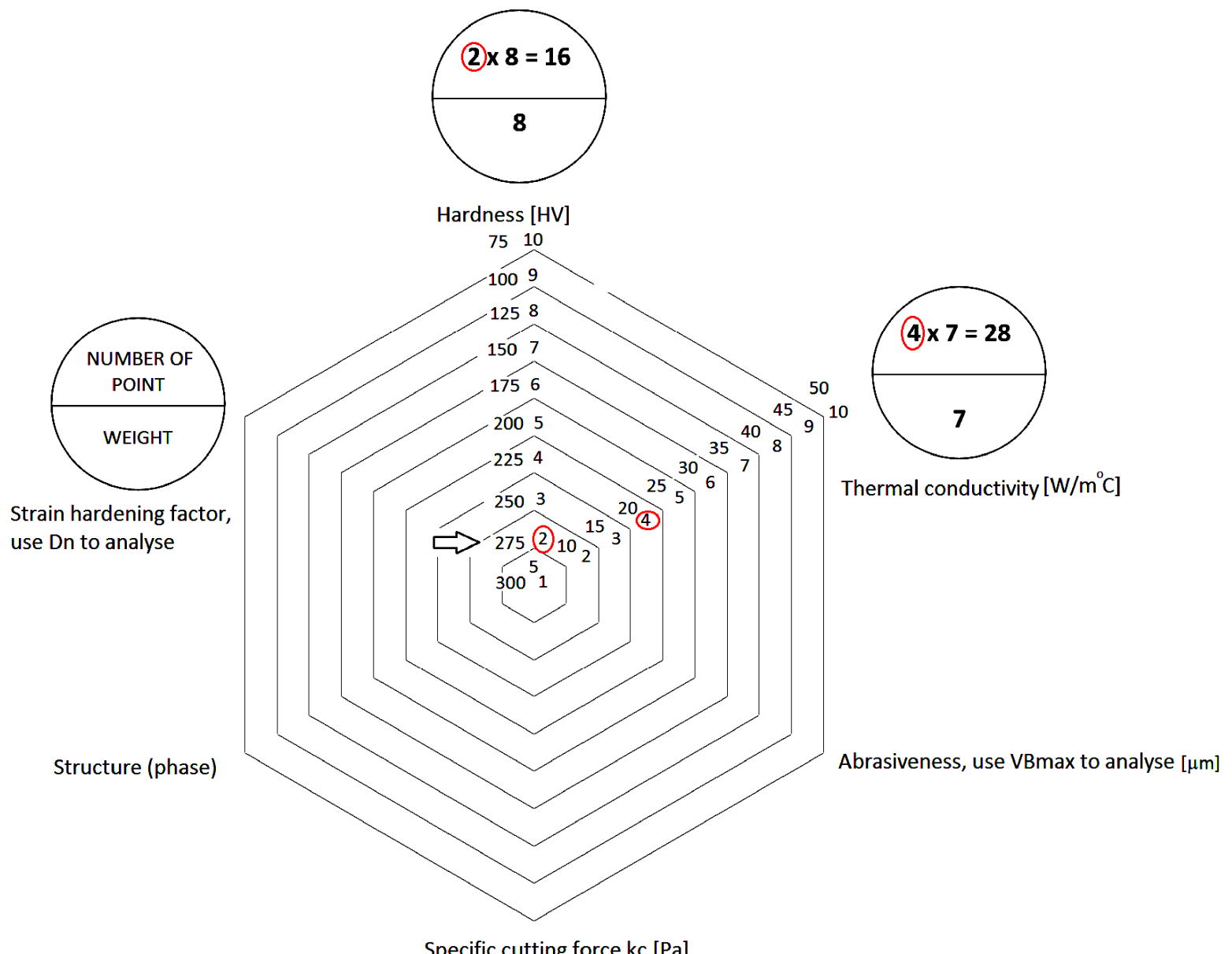

Fig. 4. The weighted radar diagram principle.

\section{The weighted radar diagram technique for evaluation of the machinability of NiTi alloy}

The materials used throughout this work were $\beta-\mathrm{Ti}_{49 \%} \mathrm{Ni}_{51 \%}$ and $\alpha-\mathrm{Ti}_{50 \%} \mathrm{Ni}_{50 \%}$ alloy. To understand the weighted radar diagram technique used to evaluation of machinability of TiNi, some important properties of TiNi alloy used in this study are presented in Table 1 (like hardness, thermal con- ductivity, abrasiveness (use $V B_{\max }$ to analyse), material structure, strain hardening factor (use $D n=$ yield strength/ultimate tensile strength to analyse) and specific cutting force $k c$ ). In Table contains the material property weigh, which is assigned by the authors based on the expert knowledge and the point number achieved by the given material property (by multiplying point number corresponding to a material property value by a weight of this property). The Figs. 5 and 6 show the results of the weighed radar diagram technique used.

Table 1

The important properties of TiNi alloy used in this study [2, 9-12 and own work e.g. measurement of cutting force].

\begin{tabular}{l|c|c}
\hline Properties of material & $\beta-\mathrm{Ti}_{49 \%} \mathrm{Ni}_{51 \%}$ & $\alpha-\mathrm{Ti}_{50 \%} \mathrm{Ni}_{50 \%}$ \\
\hline Hardness $[\mathrm{HV}]$ & 275 & 200 \\
\hline Thermal conductivity $\left[\mathrm{W} / \mathrm{m}^{\circ} \mathrm{C}\right]$ & 18 & 8.6 \\
\hline Abrasiveness, use $V B_{\max }$ to analyse $[\mu \mathrm{m}]$ & $40-120$ (average 80$)$ & $120-260$ (average 190) \\
\hline Specific cutting force $k c[\mathrm{~Pa}]$ & 5000 & 3000 \\
\hline Structure (phase) & hi-temp B2 & low-temp B19' \\
\hline Strain hardening factor, use $D n$ to analyse & 0.3 & 0.1 \\
\hline
\end{tabular}


Table 2

The material property weigh and the point number achieved by the given material property.

\begin{tabular}{|c|c|c|c|}
\hline \multirow[t]{2}{*}{ Properties of material } & \multirow[t]{2}{*}{$\begin{array}{l}\text { The material } \\
\text { property weigh }\end{array}$} & \multicolumn{2}{|c|}{$\begin{array}{l}\text { By multiplying point number corresponding } \\
\text { to a material property value } \\
\text { by a weight of this property }\end{array}$} \\
\hline & & $\alpha-\mathrm{Ti}_{50 \%} \mathrm{Ni}_{50 \%}$ & $\beta-\mathrm{Ti}_{49 \%} \mathrm{Ni}_{51 \%}$ \\
\hline Hardness $[\mathrm{HV}]$ & 8 & $2 \times 8=\mathbf{1 6}$ & $5 \times 8=\mathbf{4 0}$ \\
\hline Thermal conductivity $\left[\mathrm{W} / \mathrm{m}^{\circ} \mathrm{C}\right]$ & 7 & $4 \times 7=\mathbf{2 8}$ & $2 \times 7=14$ \\
\hline Abrasiveness, use $V B_{\max }$ to analyse $[\mu \mathrm{m}]$ & 8 & $7 \times 8=\mathbf{5 6}$ & $2 \times 8=\mathbf{1 6}$ \\
\hline Specific cutting force $k c[\mathrm{~Pa}]$ & 10 & $2 \times 10=\mathbf{2 0}$ & $6 \times 10=60$ \\
\hline Structure (phase) & 9 & $6 \times 9=\mathbf{5 4}$ & $4 \times 9=\mathbf{3 6}$ \\
\hline Strain hardening factor, use $D n$ to analyse & 5 & $6 \times 5=\mathbf{3 0}$ & $2 \times 5=10$ \\
\hline Total & & 204 & 176 \\
\hline
\end{tabular}

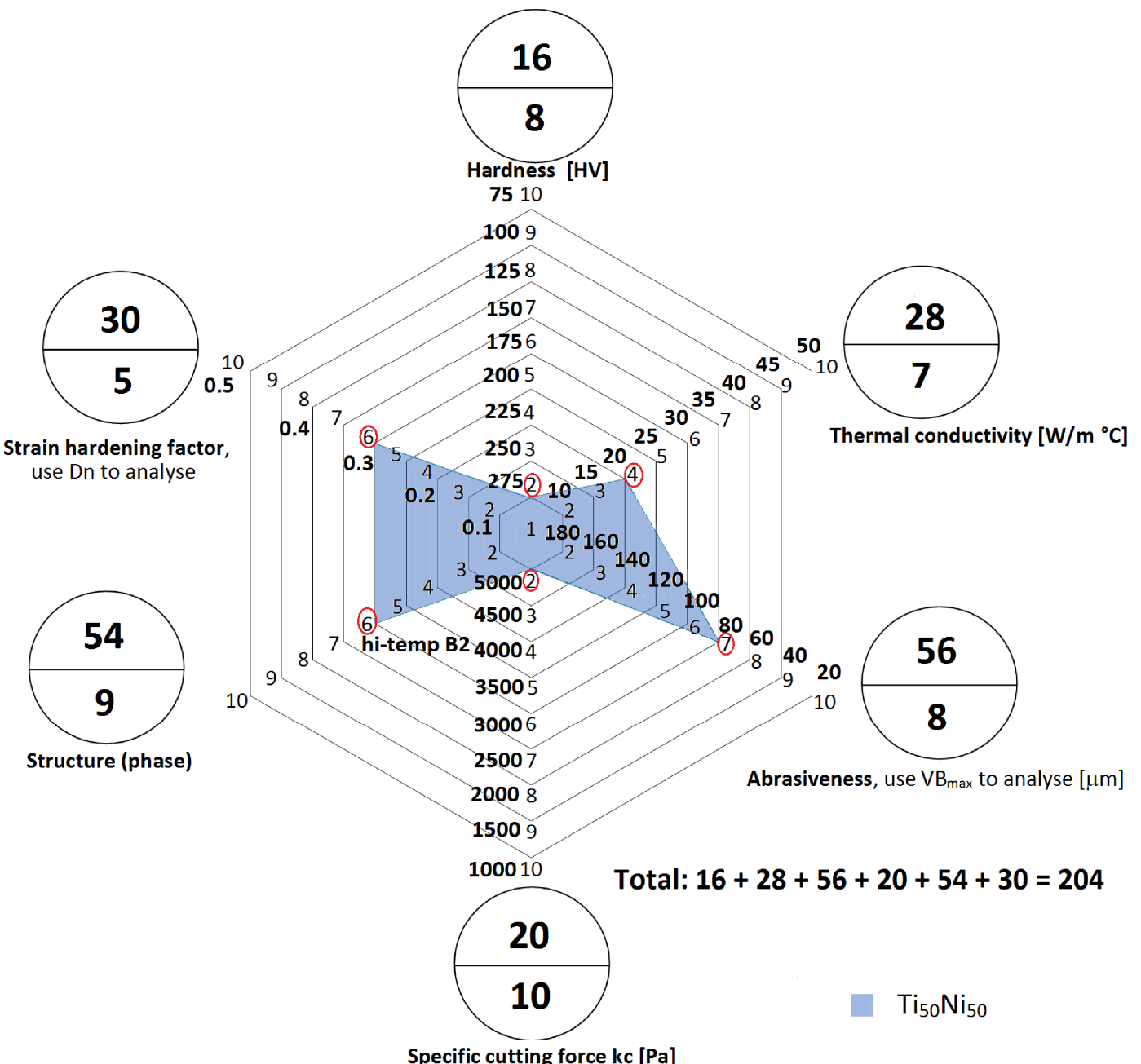

Fig. 5. The weighted radar diagram (the material property weigh and the point number achieved by the given material property for $\left.\alpha-\mathrm{Ti}_{50 \%} \mathrm{Ni}_{50 \%}\right)$. 


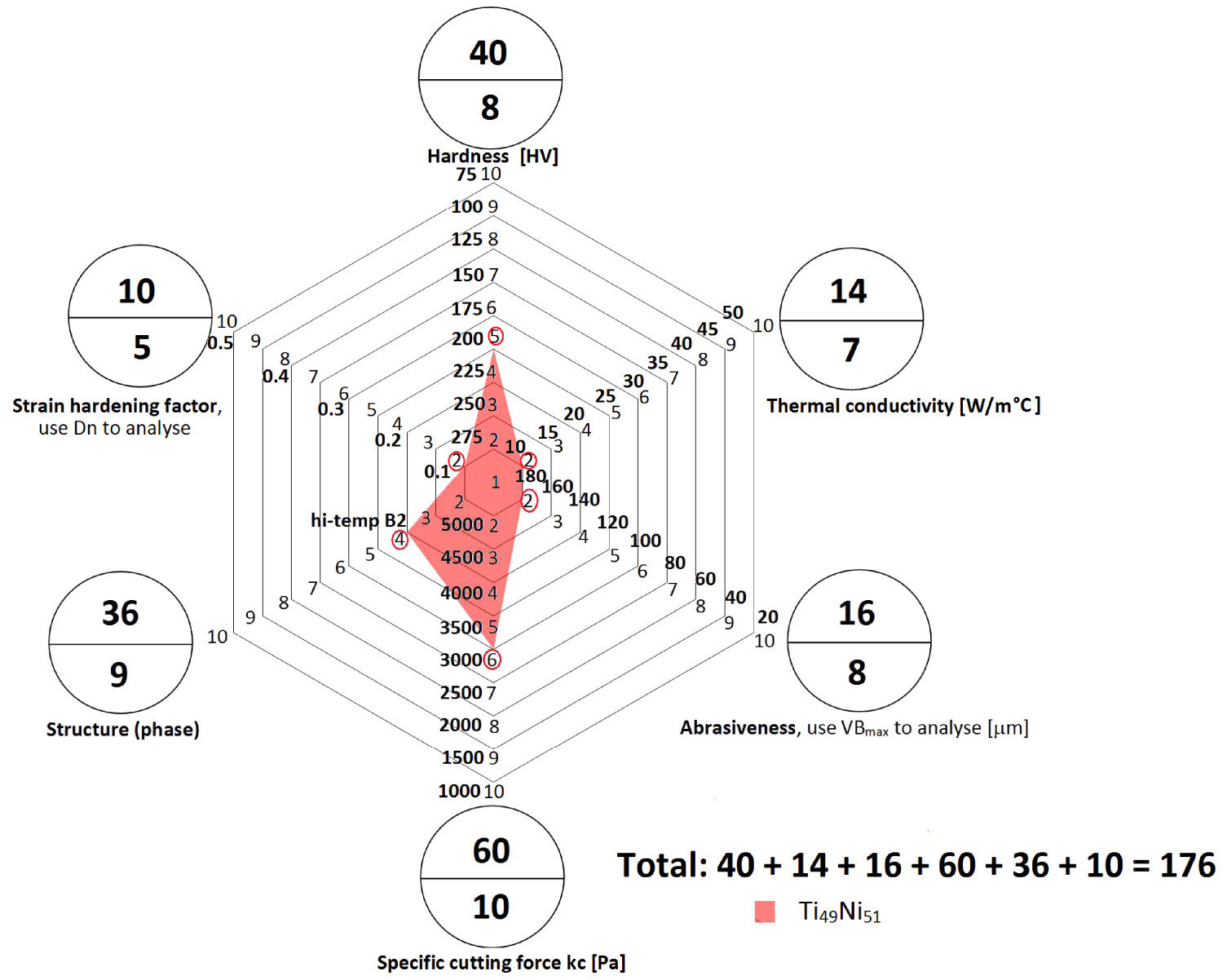

Fig. 6. The weighted radar diagram principle (the material property weigh and the point number achieved by the given material property for $\left.\beta-\mathrm{Ti}_{49 \%} \mathrm{Ni}_{51 \%}\right)$.

\section{Conclusions}

Based on conducted experiments and theoretical analyses, we can ascertain that:

- considering the current state of views on material machinability, we cannot comprehensively determine this material property in a quantitative way using only one quantity that is called machinability indicator;

- in order to assess the material machinability we have to choose the set of at least several indicators of different usage meaning (eg. energy, tribology, quality of machined part's top surface, material properties, etc.);

- the new method of material machinability assessment, as presented in the article, which uses the weighted radar diagram, fulfills the previous conclusion, because it determines the machinability by inclusion of 6 different, properly selected indicators (like hardness, thermal conductivity, abrasiveness (use $V B_{\max }$ to analyse), mater- ial structure, strain hardening factor (use $D n=$ yield strength/ultimate tensile strength to analyse) and specific cutting force $k c$ ). Moreover, the method enables to compare the machinability of materials of the same type, but different sorts, in a umerical way, which is objective and comprehensive enough. The fundamental assumption of this method is that the machining will be realized in identical or similar conditions.

- The competitive method of Seco Tools using the radar diagram, which relates the machinability of different materials to AISI/4041 (steel 45) steel machinability as a reference, shall be treated as questionable and less helpful, as different types of materials are machined in different conditions, thus having a different machinability.

- The analysis of machinability conducted using the weighted radar diagram for two different sorts of Nitinol alloy determined that $\alpha-\mathrm{Ti}_{50 \%} \mathrm{Ni}_{50 \%}$ features a worse machinability comparing to $\beta$ $\left.\mathrm{Ti}_{49 \%} \mathrm{Ni}_{51 \%}\right)$. 


\section{References}

[1] Guo Y., Klink A., Fu Ch., Snyder J., Machinability and surface integrity of Nitinol shape memory alloy, CIRP Annals - Manu. Tech., 62, 83-86, 2013.

[2] Starzynska B., Hamrol A., Excellence toolbox: Decision support system for quality tools and techniques selection and application, Total Quality Management \& Business Excellence, 24, 5, 2013.

[3] Hamrol A., Process diagnostic as a means of improving the efficiency of quality control, Production Planning \& Control, 11, 8, 797-805, 2000.

[4] Biermann D., Kahleyss F., Krebs E., Upmeier T., A study on micro-machining technology for the machining of NiTi: five-axis micro-milling and micro deep-hole drilling, JMEPEG, 20, 745-751, 2011.

[5] Kaynak Y., Robertson S.W., Karacac H.E., Jawahir I.S., Progressive tool-wear in machining of roomtemperature austenitic NiTi alloys: the influence of cooling/lubricating, melting, and heat treatment conditions, J. Mater. Process. Tech., 215, 95-104, 2015 .

[6] Kaynak Y., Karaca H.E., Noebe R.D., Jawahir I.S., Tool wear analysis in cryogenic machining of NiTi shape memory alloys: a comparison of tool wear performance with dry and MQL machining, Wear, 306, 51-63, 2013.

[7] Lin H.C., Lin K.M., Chen Y.C., A study on the machining characteristics of TiNi shape memory alloys, J. Mater. Process. Tech., 105, 327-332, 2000.

[8] Piquard R., Acunto A.D., Laheurte P., Dudzins- ki D., Micro-end milling of NiTi biomedical alloys, burr formation and phase transformation, Prec. Eng., 38, 356-364, 2014.

[9] Weinert K., Petzoldt V., Kotter D., Turning and drilling of NiTi shape memory alloys, CIRP Annals - Manuf. Technol., 53, 1, 65-68, 2004.

[10] Weinert K., Petzoldt V., Machining of NiTi based shape memory alloys, Mater. Sci. and Eng., A 378, 180-184, 2004.

[11] Weinert K., Petzoldt V., Machining NiTi microparts by micro-milling, Mater. Sci. and Eng., 481482, 672-675, 2008.

[12] Wu S.K., Lin H.C., Chen C.C., A study on the machinability of a Ti 49,6 Ni 50,4 shape memory alloy, Mater. Letters, 40, 27-3, 1999.

[13] Elahinia M.H., Hashemi M., Tabesh M., Bhaduri S.B., Manufacturing and processing of NiTi implants: a review, Prog. in Mater. Sci., 57, 911-946, 2012 .

[14] Nadolny K., Mahadi Al-Obaidi A.S, A multi-criteria methodology for effectiveness assessment of internal cylindrical grinding process with modified grinding wheels, Int. J. Adv. Manuf. Technol., pp. 1-13, 2016.

[15] Seco Tools, Adjustment of regulations - The machinability analysis system that improves the cutting effects of metal, Obr. Metalu., 2, 55-58, 2015.

[16] Niżankowski Cz., The polarized profiles of school airplanes for RP air forces, Monograph "Antiaircraft and air defense systems" OBRSM Tarnow, Cracow, pp. 299-308, 2003. 